\title{
Recycling of Industrial Waste Water for the Generation of Electricity by Regulating the Flow Control Sensor using IoT
}

\section{${ }^{1}$ Rajkumar Y, ${ }^{2}$ Kaviyaraj R, ${ }^{3}$ Karthika M S, ${ }^{4}$ Jeni Narayanan L. A, ${ }^{5}$ Saleekha, ${ }^{6}$ Ramya D}

${ }^{1}$ Department of Computer Science \& Engineering, Sri Krishna College of Engineering \& Technology, Coimbatore. Tamilnadu, India. ${ }^{2}$ Department of Computer Science \& Engineering, Sri Krishna College of Engineering \& Technology, Coimbatore. Tamilnadu, India. ${ }^{3}$ Department of Computer Science \& Engineering, Sri Krishna College of Engineering \& Technology, Coimbatore. Tamilnadu, India. ${ }^{4}$ Department of Computer Science \& Engineering, Sri Krishna College of Engineering \& Technology, Coimbatore. Tamilnadu, India. ${ }^{5}$ Department of Computer Science \& Engineering, Sri Krishna College of Engineering \& Technology, Coimbatore. Tamilnadu, India. ${ }^{6}$ Department of Computer Science \& Engineering, Sri Krishna College of Engineering \& Technology, Coimbatore. Tamilnadu, India.

Correspondence Author: Rajkumar Y, Department of Computer Science \& Engineering, Sri Krishna College of Engineering \& Technology, Coimbatore. Tamilnadu, India.

E-mail: ramya@skcet.ac.in

Received date: 14 February 2018, Accepted date: 27 April 2018, Online date: 28 April 2018

Copyright: (C) 2018 Rajkumar Y et al. This is an open-access article distributed under the terms of the Creative Commons Attribution License, which permits unrestricted use, distribution, and reproduction in any medium, provided the original author and source are credited.

\begin{abstract}
The paper focuses on generating the renewable energy source from industrial waste water effluents. Utilizing the industrial waste water in order to generate electricity, a flow control sensor has been installed at the outlet of the tunnel which pass es the waste water to the turbine. As per the need, the generation of electricity varies with respect to the flow through the use of flow control sensor. The generated electricity is then used for powering the street lights, gardening and run-way paths, during night time. The flow control sensor when integrated using IoT and cloud storage facilitates efficiency and scalability thereby providing massive utilization of energy usage.
\end{abstract}

Key words: Industrial Waste water, Micro hydro Power Plant Industry, Turbine, Renewable Energy, Flow Control Sensor, Internet of Things (IoT).

\section{INTRODUCTION}

Now-a-days the waste water discharges from industries is one of the important pollution sources in the pollution of the water environment. During the last years a huge amount of industrial waste water was discharged into rivers, lakes, and coastal areas. To treat this industrial waste water, there are different techniques available. But we can make use of this industrial waste water directly in order to generate electricity. This is a new shoot on this branch of energy production, which is capable of generating electrical energy from waste water. To make this in realistic way we have come into a smart water management model. This is totally managed by the sensors and the controllers without any human interference. The IoT sensors can monitor the water level in the tank and thereby control the flow of water. A network of smart meters that collect granular real-time data across the water tank that could help to identify the water leakage, hidden patterns in water consumption, use predictive analytics to regulate demand and supply and set up alarms for notifying anomalies. Then the water resource is proceeding for electricity generation. There are several techniques for treating waste water from industries but there is no efficient method in order to generate electricity from it. This paper introduces a new algorithm to collect and maintain industrial waste water for energy production.

\section{Literature Survey:}

Nan Win Aung [1] proposed a solution for solving the problem of fluctuation in frequency and voltage output from a generator due to variation in consumer load. The fluctuation in frequency and voltage will affect various electrical appliances adversely. The main reason for this problem is variation in speed of water turbine due to change of consumer load. The solution uses a microcontroller and liquid crystal display (LCD) to monitor the voltage, power, current and frequency of electronic load controller (ELC). ELC is a solid state electronic device which is used to regulate output power of a micro hydropower system and there by handing load on the turbine.

Asanka et.al [2] proposed a microcontroller based electronic governor and control system for mini hydro power plant, which is a complete requirement in the field of small scale power plants. This is to improve the features of mechanical governor systems and remote controllability in user friendly manner. Here it uses microcontroller technology with the electronic governor system, so it is cost effective.

Mohamed Nazih Abdallh [3] says about the best techniques for industrial waste water treatment of food industry. The industrial waste water will contain toxic materials and possibly pathogenic bacteria. So before discharging this waste water in to surface or ground water it should be fully treated. Compared to other industries the food industry requires large amount of water. The waste water from food industry causes pollution problems due to its high COD (Chemical Oxygen Demand) and BOD (Biochemical Oxygen Demand). There are mainly two treatment technique which are physical-chemical treatment and physical-chemical treatment followed by biological treatment technique. Physical-chemical treatment can remove max degree of chemical oxygen demand, biochemical oxygen demand and suspended solids from food waste water. Anaerobic digestion is one of the suitable techniques for the treatment of high strength organic effluents.

Edumund et al [4] developed a sensible and affordable system to generate a significant quantity of electric power using closed loop water power plant system. Here the proposed concept is generating electric power with the little amount of water. Hence it requires only small quantity of water; the wastage of water is minimized. The construction is very simple because it is a small power plant. It consists of two tanks with the help of external pressure. This is a fully automated 
system.

Mu Han et al [5] proposes automatic flow control technique for fluids from different industries. For the frequency input of the micro controller a sensing unit, photo interrupter and slotted disk are using. Automatic control system is method which makes the needed adjustments without human aid.

Balaji et al [6] proposed a microcontroller-based power generation from the agricultural field. That is to make agriculture simple, effective and automatic irrigation system in order to provide Water to the field based on their soil types. Here the moisture content of the soil will test using moisture sensor and the output is taken as the input of the microcontroller. By this result the microcontroller can control the motor, which is used pump the water from the ground and it will be stored in a tank. When the water reaches the tank outlet the turbine will rotate, and the motion of the turbine helps to generate the power which is done based on the hydroelectric power generation principle. The generated current can be used for the home applications and this system will preserve an optimum water distribution.

Jinhuang Huang et al [7] says about the intelligent water dispenser systems based on embedded systems. Heating and heat insulation are the main functions of current general domestic water dispenser systems. It is achieved by using the analog systems. But they have so many disadvantages such as it will affect by external environment factors. Microcontroller-based temperature monitoring and controlling is used in actual production. The MCV-based smart temperature control water dispenser system is used for the good functioning.

Hydro turbine governing system [8] in which the main controller is the Governor of the hydraulic turbine and it varies the water flow in order to control the speed or power output. The size, type and cost vary according to their capacity and performance. Here speed sensing methods are used based on speed response. The speed governor is used to maintain the water turbine speed in spite of the variation of the load. It must be high sensitivity and stability. The waste water discharged from different industries has different characteristics and volume. Different aerobic or anaerobic biological processes are applied for the treatment of industrial waste water from food industries [9]. Using nanoparticles in the industrial waste water treatment also facilitates efficient usage which removes sludge and the unwanted impurities. Analytics Hierarchy process facilitates efficient decision when these waste water accumulated in different container on different catchment basin can be scheduled effectively for the automatic monitoring and the generating the electricity. Also, to enhance the waste water treatment AHP can be modeled using DAHP protocol where after the generation of current it can be scheduled for street lights, parking areas, etc. These decisions can be made efficiently [10]. For the selection of treatment process the site conditions of the wastewater treatment plant, wastewater properties and economic efficiency of the treatment are considered.

System Architecture:

\section{METHODOLOGY:}

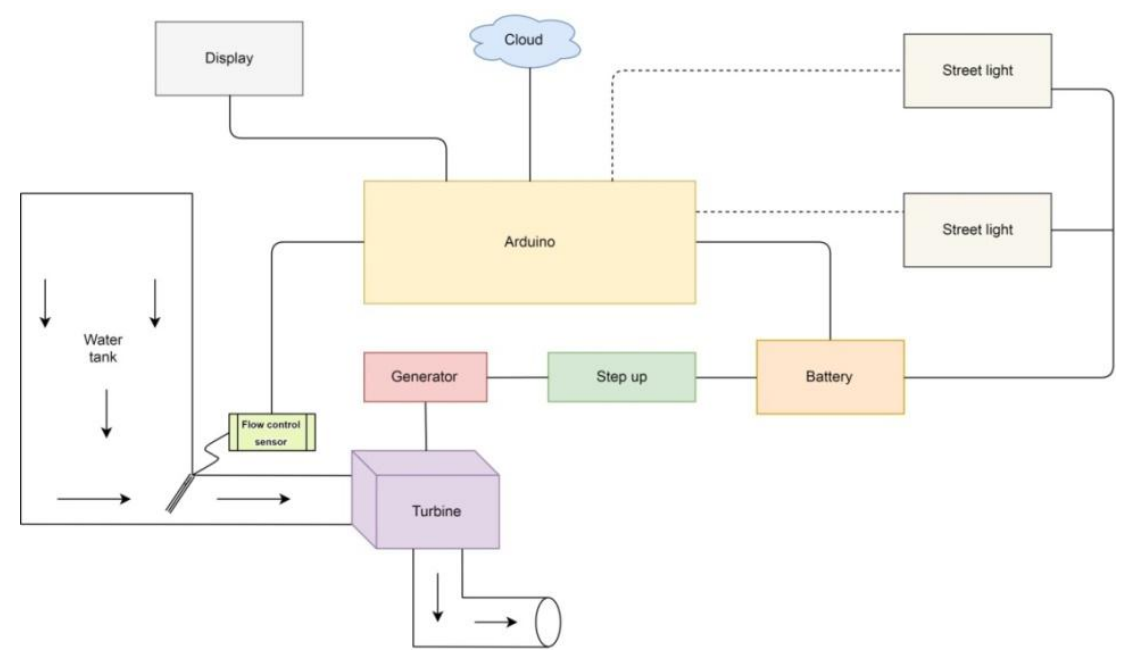

Fig. 1: System Architecture

Components:

Arduino:

Arduino is open source PC equipment and programming organization which will plan and fabricates single-board microcontrollers and microcontroller packs for building computerized gadgets that can sense and control objects in the physical and advanced world. Here it is used to control the working of flow control sensor, display, street lights. It connects with the internet and it can be access from anywhere.

Battery:

The battery used here is Lithium-Ion battery, the current generated is being stored in this battery. The amount of current in the battery will be shown on a display that is connected to the Arduino board; the stored current so obtained can be used to power up the street lights.

Cloud:

The user input to the Arduino micro-controller could be given from anywhere using the cloud infrastructure.

Display:

The Battery voltage will be displayed on the LED display. Also, the user inputs/commands will also be displayed.

Flow control sensor:

Water flow sensor is used to control the flow of water and send it to the turbine for producing the current according to the water flow. Based on the input from the user/arduino the flow of water can be controlled.

Generator:

It is used to generate the electricity from the turbine; it is done by converting the mechanical energy to electrical energy.

Step Up Transformer:

Transformer is an electrical device that transfers electrical energy between two or more circuits through the technique electromagnetic induction. In step up transformer the main task is converting high voltage and low current from the primary side to the low voltage and high current on the secondary side and vice versa.

Street light:

The lights in the industry are powered up with the electricity produced from the generator with the help of turbine. 
Turbine:

Turbine is the main part used to produce the electricity from the flow of water. It is a machine which works by the action of fluid and it contains a circular set of blade. The moving fluid acts on the blades which spins turbine connected to the generator to produce electricity.

Methodology:

Step-1: Start and connect a microcontroller to the internet via wifi.

Step-2: Collect the industrial waste water in the tank.

Step-3: Based on the output of the flow control sensor it will work.

Step-4: The water will flow into the turbine and it starts spinning.

Step-5: The rotation of the turbine will produce electricity in the generator.

Step-6: The step up transformer is used to amplify the generated energy.

Step-7: The electrical energy is stored in lithium-ion battery and the voltage can be viewed in display.

Step-8: The energy stored in the battery is used to power up the street light.

Let the catchment basin be represented as $\delta$. The water flow in the catchment basin varies with respect to time which can be defined as $d(\delta)$. The energy produced or the current generated is directly proportional to the kinetic energy, potential energy and the flow inside and outside the catchment basin. Therefore, the level of current produced can be defined as

$$
\mathrm{y} 1 / \mathrm{t}+\mathrm{tv} 1+1 / 2 \mathrm{~g}_{1} \wedge 2=\mathrm{y} 2 / \mathrm{t}+\mathrm{tv} 2+1 / 2 \mathrm{~g}_{2} \wedge 2
$$

Since the potential, kinetic and the mechanical energy vary with respect to time which remains constant $\mathrm{n}$ both the outside of the catchment basin as well as the inside of the basin, the output will be constant.

$\mathrm{y} / \mathrm{t}+\mathrm{tv}+1 / 2 \mathrm{~g}^{\wedge} 2=\mathrm{k}$

Since the water level varies with respect to time and rate of flow of waste water, this change in fluctuation can be defined as

$(\mathrm{d}(\mathrm{y})) / \mathrm{t}+\mathrm{Vtv}+\mathrm{gdz}=0$

Since the tank is open to the atmosphere

$\mathrm{y} 1=\mathrm{y} 2$

The rate at which the water comes into the catchment basin will be presumed as zero

$\mathrm{v} 1=0$

Therefore, the energy produced varies with respect to the flow or rate of flow of water and the moment at which the power can be generated are as follows:

$\mathrm{v} 2=\sqrt{ }(2 \mathrm{y}(\mathrm{z} 1-\mathrm{z} 2))=\sqrt{2} \mathrm{gm} \quad \mathrm{m}=+\mathrm{pAV}$

$\left(\mathrm{v}_{2} \wedge 2-\mathrm{v}_{1} \wedge 2\right) / 2 \mathrm{~g}=\mathrm{k}$

The energy production also changes with respect to the kinetic energy when it moves inside the pump to the turbine which can be defined as

$$
\begin{gathered}
\mathrm{P} 1+\gamma_{\mathrm{w}} \mathrm{Z}_{\mathrm{o}}+\gamma_{\mathrm{m}} \mathrm{Z}=\mathrm{P} 22+\gamma_{\mathrm{w}} \mathrm{z}_{\mathrm{o}}+\gamma_{\mathrm{m}}{ }^{\wedge} \mathrm{z} \\
\mathrm{P} 2-\mathrm{P} 1=\left(\gamma_{\mathrm{m}}-\gamma_{\mathrm{w}}\right) \mathrm{z}
\end{gathered}
$$

$\mathrm{h}_{\mathrm{A}}=(\mathrm{P} 1-\mathrm{P} 2) / \gamma_{\mathrm{w}}+\mathrm{v}_{2} \wedge 2-\left(\mathrm{v}_{1} \wedge 2\right) / \mathrm{g}$

Therefore, the power generation can be defined as

Power $\mathrm{P}=\gamma_{\mathrm{w}} \mathrm{Qh}_{\mathrm{A}}$

The efficiency or the current produced can be given as

Efficiency $=\mathrm{P} /$ Pumpout

\section{CONCLUSION:}

Since we are running out of renewable energy resources, its high time that to go for methods that preserves them. The idea proposed here would produce electricity from industrial waste water which could be then used to light up streets. Innovative technologies could be used to extend this idea further for large scale electricity generation. Further, if turbine can be powered up, the electricity generation can be increased in large a quantity which facilitates powering up the street lights, gardens, parking areas, terraces, roofing's, verandas, extra spaces etc.

\section{REFERENCES}

[1] Microcontroller Based Electrical Parameter Monitoring System of Electronic Load Controller Used in Micro Hydro Power Plant, 2015. Journal of Electrical and Electronic Engineering, 3(5): 97-109.

[2] LPG Asanka, DMH Colombage, MHRH de Silva, SHN Tharanga "Microcontroller based Electronic Governor and Control System of a Mini-hydro Power Plant" Department of Electrical Engineering, University of Moratuwa.

[3] Mohamed Nazih Abdallh, Walid Sayed Abdelhalim, Hisham Sayed Abdelhalim, 2016. "Industrial Wastewater Treatment of Food Industry Using Best Techniques" International Journal of Engineering Science Invention ISSN (Online): 2319 - 6734, ISSN (Print): 2319 - 6726, www.ijesi.org Volume 5,Issue 8, August, pp: 15-28.

[4] Edmund laal, M.F., K. Mahesh kumar, M. Suresh, G. Saravanan, G. Deenadayalan, 2013. "Closed Loop Water Power Plant” International Journal of Scientific \& Technology Research, 2(10): ISSN 2277-8616.

[5] Thwe Mu Han, Ohn Mar Myaing "Design and Construction of Microcontroller-Based Water Flow Control System, 2011. "2011 International Conference on Circuits, System and Simulation IPCSIT vol.7 (2011) @ IACSIT Press, Singapore.

[6] Balaji S., E.L. DhivyaPriya, G. Durairaj, V. Illakkiya, 2015. "Microcontroller Based Power Generation from the Agricultural Field" International Journal of Advanced Research in Electronics and Communication Engineering (IJARECE) 4: 4.

[7] Huang, Jinhuang, and Jun Xie, 2010. "Intelligent water dispenser system based on embedded systems."Mechatronics and Embedded Systems and Applications (MESA), 2010 IEEE/ASME International Conference on. IEEE.

[8] Rehab, M., El-Hefny, Mohamed N. Ali, Ahmed M. Fouad, 2018.” Application of A New Technology For Dairy Processing Wastewater Treatment Using Activated Sludge", Australian Journal of Basic and Applied Sciences, 12(3): 35-42 DOI: 10.22587/ajbas.2018.12.3.5.

[9] Muhammad Ishak Cenne, Abdul Hakim, Endah Setyowati, Andi Tamsil, 2017." Analytical Hierarchy Process on the Community-based Management of Household Waste in Tamalate, Makassar", Australian Journal of Basic and Applied Sciences, 11(10): 20-25.

[10] Rajkumar Y," 2016. Agent based Dynamic Analytical Hierarchy Routing Protocol for Vehicular Ad hoc Networks " International Journal of Computer Science and Information Technologies, 7(5): 2175-2182. 